\title{
Thermo-hydraulic coupled analysis of meshed district heating networks based on improved breadth first search method
}

\author{
Yaran Wang a, b, 1, Kaiyu Shi a, b, 1, Xuejing Zheng a, b, *, Shijun You ${ }^{\text {a, b }}$, Huan Zhang a, b, Chengzhi Zhu ${ }^{\text {c, }}$ \\ Liang Li ${ }^{\text {c }}$, Shen Wei ${ }^{\text {d, Chao Ding }}{ }^{\text {a }}$, Na Wang ${ }^{\text {a }}$ \\ a School of Environmental Science and Engineering, Tianjin University, Haihe Education Area, Jinnan \\ District, Tianjin 300350, PR China. \\ b Tianjin Key Lab of Biomass/Wastes Utilization, Tianjin 300350, PR China. \\ c Shijiazhuang Huadian Heating Group Co. Ltd., Shijiazhuang 050041, Hebei Province, PR China. \\ d The Bartlett School of Construction and Project Management, University College London (UCL), 1-19 \\ Torrington Place, London WC1E 7HB, United Kingdom. \\ ${ }^{*}$ Corresponding Author: Tel. / Fax: +86 222740 0832. E-Mail address: zhengxuejing@tju.edu.cn.
}

\begin{abstract}
Efficient numerical simulation of thermo-hydraulic coupled conditions is critical for analysis and control of DH network. However, for most of meshed DH network, the flow directions of its pipelines may change, which will lead to difficulties in effective numerical calculation of the thermo-hydraulic conditions. This paper established an efficient thermo-hydraulic coupled calculation method, which utilizes the topology sorting algorithm to obtain the calculation sequence of all pipelines during numerical thermal transient calculation, according to the flow directions and flow rates of all pipelines. The flow directions and flow rates are solved by hydraulic condition
\end{abstract}

\footnotetext{
1 Joint first authors.

${ }^{*}$ Corresponding author. Tel.: +8602227892626; fax: +8602227892626.

E-mail addresses: yaran_wang@tju.edu.cn
} 
calculation at each time step. The proposed method is applied to a real meshed DH network for thermal dynamic simulation. Independence analysis of hydraulic computation frequency is conducted, and convergences of the simulated temperature variations are observed when hydraulic computation frequency gets larger. Thermal dynamics of the meshed $\mathrm{DH}$ network are analyzed with ten-minute hydraulic computation interval. Results show that the temperature decay and time delay can be up to $2.7^{\circ} \mathrm{C}$ and 210 minutes for the simulated network. Thermal dynamic characteristics of supply temperature waves are various considering the distance from heat source, fluctuations of outdoor temperature and the variations of substation flow rate.

Keywords: meshed district heating network, topology sorting, improved breadth first search method, thermo-hydraulic coupled model, hydraulic computation frequency, thermal dynamics

\begin{tabular}{|c|l|c|l|}
\hline \multicolumn{2}{|l|}{ Nomenclature } \\
\hline$A$ & basic incidence matrix & $G$ & flow rate vector of branches $(\mathrm{kg} / \mathrm{s})$ \\
\hline$Q$ & flow rate vector of nodes $(\mathrm{kg} / \mathrm{s})$ & $B_{f}$ & independent loop matrix \\
\hline$C_{1}, C_{2}, C_{3}$ & $\begin{array}{l}\text { coefficient matrices of circulating } \\
\text { pump head }\end{array}$ & $H_{p}$ & $\begin{array}{l}\text { head vector of circulating pump } \\
\left(\mathrm{mH}_{2} \mathrm{O}\right)\end{array}$ \\
\hline$\Delta P$ & pressure drop vector of branch & $A_{0}$ & cross section area of the fluid $\left(\mathrm{m}^{2}\right)$ \\
\hline$A_{1}$ & branched matrix & $A_{2}$ & residual matrix \\
\hline$G_{1}$ & branched flow rate $(\mathrm{kg} / \mathrm{s})$ & $G_{2}$ & residual flow rate $(\mathrm{kg} / \mathrm{s})$ \\
\hline$G^{k}$ & $\begin{array}{l}\text { branch flow rate vector in } k \text { th } \\
\text { iteration }(\mathrm{kg} / \mathrm{s})\end{array}$ & $\Delta G^{k}$ & $\begin{array}{l}\text { improved branch flow rate vector in } k \text { th } \\
\text { iteration }(\mathrm{kg} / \mathrm{s})\end{array}$ \\
\hline$\lambda$ & thermal conductivity $\left(\mathrm{W} /\left(\mathrm{m} \cdot{ }^{\circ} \mathrm{C}\right)\right)$ & $U$ & three-dimensional flow velocity $(\mathrm{m} / \mathrm{s})$ \\
\hline$T$ & three-dimensional temperature $\left({ }^{\circ} \mathrm{C}\right)$ & $c_{p}$ & $\begin{array}{l}\text { specific heat capacity of hot water } \\
\left(\mathrm{J} /\left(\mathrm{kg} \cdot{ }^{\circ} \mathrm{C}\right)\right)\end{array}$ \\
\hline
\end{tabular}




\begin{tabular}{|c|l|c|l|}
\hline$S_{T}$ & internal heat source & $u$ & hot water velocity $(\mathrm{m} / \mathrm{s})$ \\
\hline$\rho$ & hot water density $\left(\mathrm{kg} / \mathrm{m}^{3}\right)$ & $T_{0}$ & soil surface temperature $\left({ }^{\circ} \mathrm{C}\right)$ \\
\hline$T_{i}^{n}$ & $\begin{array}{l}\text { temperature of the control volume } i \\
\text { at time step } n\left({ }^{\circ} \mathrm{C}\right)\end{array}$ & $R$ & total thermal resistance $\left(\mathrm{m} \cdot{ }^{\circ} \mathrm{C} / \mathrm{W}\right)$ \\
\hline$T_{i n}$ & inflow temperature of node $\left({ }^{\circ} \mathrm{C}\right)$ & $T_{\text {out }}$ & outflow temperature of node $\left({ }^{\circ} \mathrm{C}\right)$ \\
\hline$m$ & mass flow rate $(\mathrm{kg} / \mathrm{s})$ & $G_{v i}$ & primary mass flow ratio \\
\hline$S$ & hydraulic resistance $\left(\mathrm{Pa} /(\mathrm{t} / \mathrm{h})^{2}\right)$ & $T_{w}$ & outdoor temperature $\left({ }^{\circ} \mathrm{C}\right)$ \\
\hline$N$ & control volume number & $D$ & internal pipe diameter $(\mathrm{mm})$ \\
\hline$q$ & traversal queue & $V_{\text {result }}$ & traversal result vector \\
\hline$F_{f l a g}$ & accessed flag vector & $P_{k}$ & index matrix \\
\hline$t_{g 2}$ & secondary supply temperature $\left({ }^{\circ} \mathrm{C}\right)$ & $t_{g 1}$ & primary supply temperature $\left({ }^{\circ} \mathrm{C}\right)$ \\
\hline$t_{h 1}$ & primary return temperature $\left({ }^{\circ} \mathrm{C}\right)$ & $t_{h 2}$ & secondary return temperature $\left({ }^{\circ} \mathrm{C}\right)$ \\
\hline
\end{tabular}

\section{Introduction}

District heating (DH) system is attracting increasing interest for the potential environment and energy efficiencies [1]. As an essential infrastructure of modern urban facilities, DH system functions in heat delivery via distributed underground pipe network [2]. With the complexity of DH networks increasing and the requirements of energy conversation enhancing, regulation flexibilities of DH system are far more important [3, 4], which are largely dependent on the efficient analysis of tightly connected hydraulic and thermal conditions [5]. Hence, studies on thermo-hydraulic coupled analysis of DH networks are imperative.

\subsection{Literature overview}


An overview of previous literature on the topic of hydraulic and thermal conditions of DH network is provided in this section. And the literatures are chronologically organized via modelling methods.

\subsubsection{Steady-state hydraulic analysis}

Steady-state hydraulic models are widely utilized based on graph theory, while dynamic hydraulic models are merely required for the analysis of water hammer phenomena [6]. By solving the steady-state hydraulic model, distributions of flow rates and pressure within DH network can be obtained. There are mainly three kinds of methods for the solution of steady-state model, Hardy Cross method, node method and Newton-Raphson method. Hardy Cross method is applicable for hand calculations, since each loop of the whole network is considered independently. As for node method, simulation results are particularly sensitive to the initial conditions, and this method is inapplicable to low resistance pipelines [7].

As a combination of Newton-Raphson method and loop corrective flows, loop method is widely applied for its high calculation efficiency [8-13]. Stevanovic et al. [7]. presented an efficient method for the steady-state hydraulic simulation based on loop method. Comparisons were conducted between loop method and Hardy Cross method by means of computing time and iterative number. Results show that the loop method is more applicable to the steady-state hydraulic calculations of complex DH networks. Yan et al. [14] developed an improved hydraulic model to simulate the hydraulic performance of distributed variable-speed-pumps DH system. Results show that the 
model is capable of predicting hydraulic behavior. A reduced model on the basis of proper orthogonal decomposition combined with radial basis functions was presented by Guelpa et al. [15] to optimize the pumping system. Computing time could be reduced to $20 \%$ while maintaining high accuracy based on the proposed approach.

\subsubsection{Dynamic thermal analysis}

Recent studies on thermal transient modeling attract many researchers, since efficient operations of DH network are largely influenced by the dynamic temperature transportation. Two types of methods are generally utilized to simulate thermal dynamics of DH networks, namely statistic-based method and mechanism modeling method [16]. Numerous measured data are required to achieve satisfying accuracy for the statistic-based method. And this kind of models are deficient in clearly describing the intrinsic physical properties and operation mechanism of DH network, which is important for operation analysis and fault diagnosis. As for mechanism modeling method, dynamic temperature variations within DH network can be described based on the transient heat transfer of pipeline, which can convey more intrinsic properties of DH network.

As a kind of mechanism method, lumped parameter model was studied on the early stage, of which the whole pipe is considered as a single control volume. However, the distributed parameter characteristics fail to be described with lumped model [17]. Node model is further developed for the thermal transient modeling of DH pipeline. In this model, fluctuations of pipeline outlet temperature wave are basically dependent on that 
of the inlet. And the time delay of temperature propagation is calculated by the flowing time of hot water within pipeline. Gabrielaitiene et al. [18] simulated the dynamic thermal characteristics of DH network with the utilization of node model and the software TERMIS. They also studied the influence of sudden changed supply temperature on thermal transients of DH networks based on node model [19]. Node model performs well on fast simulation of thermal transients, but the temperature distribution along DH pipeline could not be precisely captured with this method. As for numerical method, more detailed information of $\mathrm{DH}$ pipeline can be provided with the partial differential equation (PDE) directly solved [17], among which the finite volume method (FVM) is widely adopted for thermal transient analysis. Wang et al. [17] studied the optimal spatial and time steps of the characteristic line model and the first-order implicit upwind model for fast and accurate prediction of $\mathrm{DH}$ pipeline thermal dynamics. Analogous to electromagnetic transient analysis method, matrix formulas were established by Hao et al. [20] to describe the thermal dynamics of DH networks. Schwarz et al. [21] proposed a modified FVM for the prediction of DH pipeline thermal transients, of which the heat loss and thermal storage of pipeline were calculated with the electrical analogy of DH system.

\subsubsection{Thermo-hydraulic coupled analysis}

As far as the thermo-hydraulic coupled conditions, efficient modellings are required for the flexible operation and management of DH network. And this topic has attracted increasing interests for researchers [22-26]. Oppelt et al. [27] established a 
quasi-static hydraulic model and a dynamic thermal model of district cooling networks based on Lagrange method. Validation results showed that the coupled model performed well in numerical accuracy. But the proposed model was conducted on the assumption of unmeshed networks, which limited its application to meshed networks. Liu et al. [28] established a thermo-hydraulic model for the analysis of DH networks. In this coupled model, thermal model was solved upon the hydraulic simulation results. And the hydraulic model was solved iteratively with hydraulic parameters updated by the newly obtained thermal simulation results. However, steady-state thermal model was adopted, of which the dynamic thermal characteristics could not be efficiently reflected. In addition, the thermo-hydraulic coupled calculation procedure was also provided in Ref. [6]. Steady-state hydraulic model and transient thermal model were adopted in this study, while the presented numerical method was explicit, and the Courant-Friedrichs-Lewy condition must be satisfied for this method [22]. Guelpa et al. [29] presented a thermo-fluid dynamic model for the simulation of large-scale meshed DH networks, and the SIMPLE algorithm was adopted to solve the hydraulic model.

\subsection{Research motivation}

Efficient regulation of DH network requires modelling networks both thermally and hydraulically, and the main idea of existing methods focus on simultaneously solving the nonlinear mass conservation equation and the energy conservation equation for all nodes and branches, which could be time-consuming for complex DH networks. Therefore, the approach of handling pipelines sequentially is proposed in this paper to 
ensure efficient thermal dynamic simulation of DH networks, which requires the reliable calculation sequence of all pipelines especially for meshed DH networks. For meshed DH networks, the flow directions of its pipelines may change and the difficulties in effective numerical calculation of the thermo-hydraulic conditions will be accordingly caused. In this paper, the thermo-hydraulic coupled model is developed based on the topology sorting of $\mathrm{DH}$ pipelines according to their flow directions by breadth first search (BFS) method, which can achieve correct calculation sequence of DH pipelines and ensure accurate inlet boundary conditions of all pipelines.

\section{Methods}

The thermo-hydraulic coupled model is essential for thermal dynamic analysis of DH networks [6]. And the hydraulic condition is generally calculated first, then the results of hydraulic model are substituted into thermal part [28]. Based on the updated primary supply temperature of substations calculated in thermal part at previous interval, hydraulic model can be solved iteratively. The loop method is applied in this paper, since the propagation speed of pressure wave can be up to $1000 \mathrm{~m} / \mathrm{s}$, which is much bigger than that of the temperature wave $[6,22]$. And the first-order implicit upwind method is adopted for the analysis of dynamic thermal characteristics.

Besides, the thermal dynamics of primary DH networks are analyzed, since the transmission delay of primary network is generally more obvious than that of the secondary [30]. And the heat source supply temperature is assumed to be reliably regulated in accordance with the outdoor temperature fluctuations. Since the 
temperature dynamics of the primary supply network governs the heat transportation performances of the DH network, the thermal dynamics of return network can be neglected, when analyzing the heat transportation performances of the DH network. Besides, the supply temperatures at the heat sources are maintained at specific setpoints by the heat source weather compensators and effective heat output regulation, hence, the supply and return networks are thermally-decoupled by the heat compensation of the heat sources. And the heat source circulation pumps are controlled to maintain the specific flows and pressures to ensure the available pressure drop of most unfavorable consumer, hence, the supply and return networks are hydraulically-decoupled by the adjustment of heat source circulation pumps. Therefore, the return network is not modeled in this paper.

For simplicity, the following assumptions are considered:

(1) The hot water is incompressible fluid;

(2) There is no leakage along the pipelines;

(3) The density of hot water and thermal conductivity are constant;

(4) The uneven radial temperature distribution and heat conduction along pipe length are ignored.

\subsection{Hydraulic model}

Graph theory is widely used to establish the mathematical description of meshed DH networks [8-11], which can be regarded as a collection of nodes connected by the directed branches. For simplicity, heat source and substations are also considered as 
nodes, and the simplified pipes are adopted with valves and other fittings neglected [31]. According to the Kirchhoff's current law, the net flow rate of individual node equals zero, which means the entered mass flow rate of node is equal to that of the leaving. For the whole hydraulic network, the following matrix equation can be obtained [32]:

$$
A G=Q
$$

where $A$ represents the basic incidence matrix, and the element $a_{i j}$ of $A$ denotes the relationship between branch $j$ and node $i$. If branch $j$ and node $i$ are not adjacent then $a_{i j}=0$. But if the node $i$ and branch $j$ are adjacent and the hot water flows from branch $j$ to node $i$ then $a_{i j}=1$, otherwise $a_{i j}=-1, G$ and $Q$ represent the flow rate vectors for the whole branches and nodes of DH network.

For each closed loop in network graph, the algebraic sum of branches' pressure drops equals zero based on the Kirchhoff's voltage law. Therefore, the loop pressure balance matrix equation is written as follow:

$$
B_{f}\left(\Delta P-H_{p}\right)=0
$$

where $B_{f}$ represents the independent loop matrix, the element $b_{i j}$ denotes the relationship between branch $j$ and loop $i, b_{i j}=0$ when branch $j$ is not in loop $i$, $b_{i j}=1$ when the direction of hot water within branch $j$ is the same as the direction of loop $i$, and $b_{i j}=-1$ when flow inversely. $\Delta P$ represents the pressure drops of all branches, which can be determined by Darcy-Weisbach formula [10], $H_{p}$ represents head vector of circulating pumps, for the branch $j$, the value of $H_{p j}$ equals zero when 
there is no circulating pump, and if the circulating pump exists, the corresponding head $H_{p j}$ is expressed as follow:

$$
H_{p}=C_{1} G^{2}+C_{2} G+C_{3}
$$

where $C_{1} 、 C_{2} 、 C_{3}$ are the coefficient matrices of circulating pump head, which can be determined by the regression method via operation data.

Eq. (1) and (2) describe the hydraulic condition of DH network, which can be solved with topological structure of network and flow rates of each node. In this paper, the loop method is applied for the solution of the nonlinear hydraulic model.

Divide $A$ into branch matrix and residual matrix based on the graph theory and $G$ is blocked accordingly, Eq. (3) is therefore rewritten as follow:

$$
\left[A_{1}, A_{2}\right]\left[\begin{array}{l}
G_{1} \\
G_{2}
\end{array}\right]=Q
$$

where $A_{1}$ is branch matrix, $A_{2}$ is residual matrix, $G_{1}$ is branch flow rate and $G_{2}$ is residual flow rate. Considering $A$ is invertible, Eq. (4) can be rearranged:

$$
G_{1}=-A_{1}^{-1} A_{2} G_{2}+A_{1}^{-1} Q
$$

Eq. (5) indicates that $G_{1}$ can be determined by $G_{2}$ and $Q$ for the specific DH network. And iterative procedures are required for obtaining satisfying hydraulic solution. Assuming $G^{k}$ as the flow rate vector of branches in $k$ th iteration, $\Delta G^{k}$ is the improved flow rate vector of branches in $k$ th iteration, flow rate vector of branches in $(k+1)$ th iteration $\left(G^{k+1}\right)$ is expressed as:

$$
G^{k+1}=G^{k}+\Delta G^{k}
$$

Combine Eq. (5) and Eq. (6), following expressions are obtained: 


$$
\begin{gathered}
\Delta G_{1}^{k}=-A_{1}^{-1} A_{2} \Delta G_{2}^{k} \\
\Delta G^{k}=B_{f}^{T} \Delta G_{2}^{k}
\end{gathered}
$$

where $\Delta G_{1}^{k}$ and $\Delta G_{2}^{k}$ denote the improved branch and residual flow rates in the $k$ th iteration.

Substitute Eq. (6) into Eq. (2) and the following equations yield:

$$
\begin{gathered}
M^{k} \Delta G_{2}^{k}=-\Delta h^{k} \\
M^{k}=B_{f}\left(2 S\left|G^{k}\right|-2 C_{1}\left|G^{k}\right|-C_{2}\right) B_{f}^{T} \\
\Delta h^{k}=B_{f}\left(S\left|G^{k}\right| G^{k}-C_{1}\left|G^{k}\right| G^{k}-C_{2} G^{k}-C_{3}\right)
\end{gathered}
$$

where $S$ is hydraulic resistance.

Hydraulic model can be solved iteratively based on Eqs. (6), (8) and (9). And the calculation flowchart is shown in Fig. 1. As is shown, with the topology of DH network and the flow rates of substations, hydraulic model can be solved. $G_{1}$ is calculated first based on Eq. (5), then $G^{k}$ is updated iteratively until $\Delta G_{2}^{k}<0.0001$. 


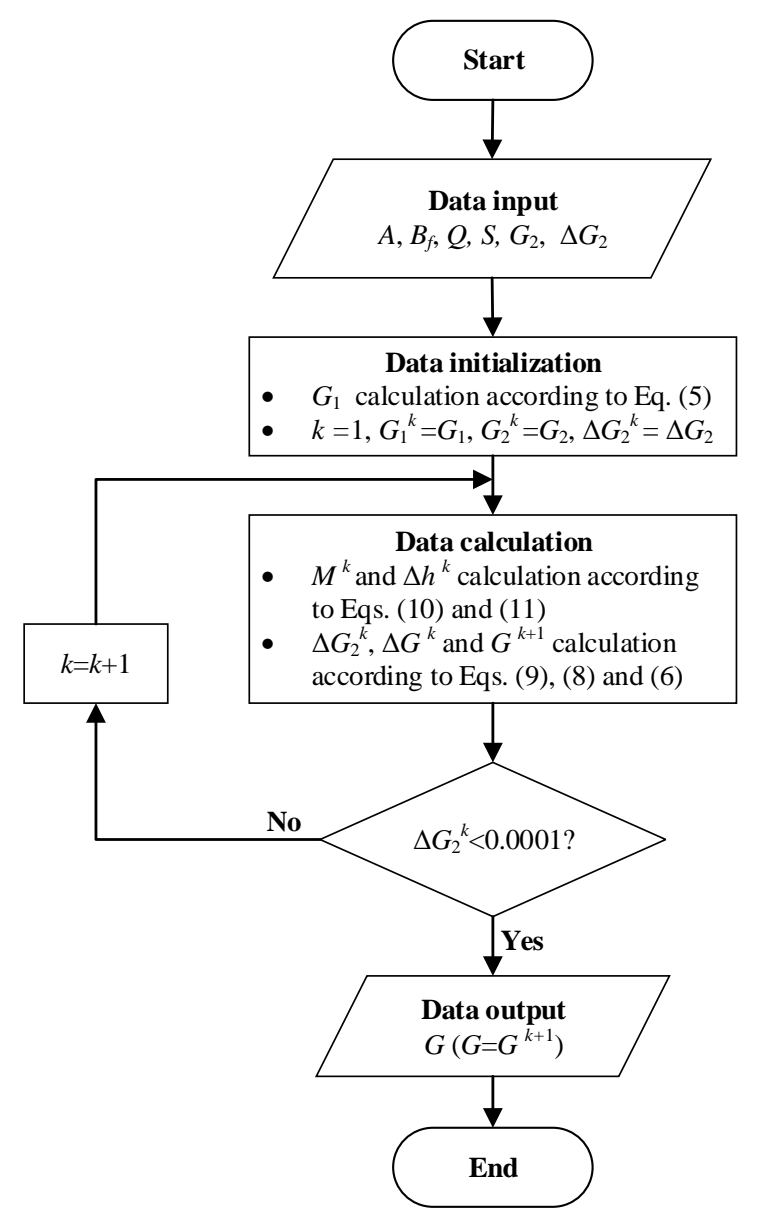

Fig. 1. Flowchart of hydraulic calculation

\subsection{Thermal model}

For a single pipeline, hot water is governed by the law of energy conservation:

$$
\frac{\partial(\rho T)}{\partial t}+\nabla \cdot(\rho U T)=\frac{\lambda}{c_{p}} \nabla^{2} T+S_{T}
$$

where $T$ represents three-dimensional temperature field within pipeline, $\rho$ represents density of hot water, $U$ represents three-dimensional flow velocity, $\lambda$ represents thermal conductivity, $c_{p}$ represents specific heat capacity of hot water and $S_{T}$ represents internal heat source of pipeline. 
Temperature vector field variation in DH pipeline can be described by Eq. (12).

Considering the assumptions in Section 2, removing the neglected terms, then the following one-dimensional form yields:

$$
\frac{\partial T}{\partial t}+u \frac{\partial T}{\partial x}=\frac{1}{\rho A_{0} c_{p} R}\left(T_{o}-T\right)
$$

where $u$ represents hot water velocity, $A_{0}$ represents the cross section area of fluid, $T_{0}$ represents soil surface temperature, which is assumed to be equal to the ambient temperature [33], and $R$ represents the total thermal resistance from hot water to ambient environment, which can be calculated based on Refs. [31, 34].

In this paper, FVM is adopted to solve Eq. (13), where the solution domain is divided into numerous control volumes and uniform distributions of the unsolved variables within each control volume are assumed. For DH pipeline, control volumes are divided as shown in Fig. 2.

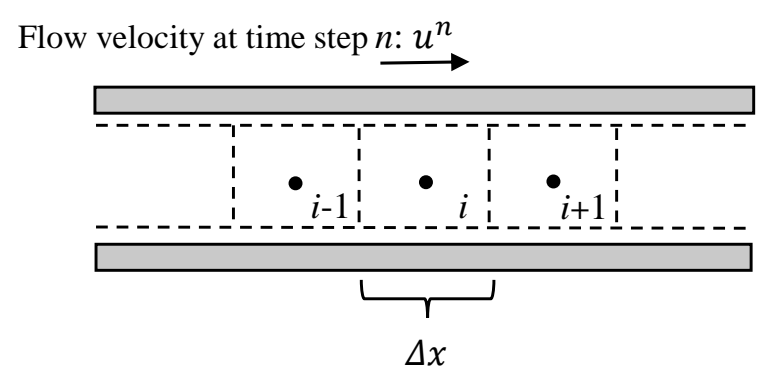

Fig.2. Control volume division of hot water within DH pipeline

The first-order implicit upwind scheme is used to discretize the spatial term, of which the effectiveness has been validated in Ref. [17], where the prediction error can be restricted within $\pm 0.5^{\circ} \mathrm{C}$ and the differential form is expressed as: 


$$
u^{n} \frac{\partial T}{\partial x}=u^{n} \frac{T_{i}^{n}-T_{i-1}^{n}}{\Delta x}
$$

where $u^{n}$ denotes hot water velocity at the $n$th time step, $T_{i}^{n}$ denotes the temperature of the control volume $i$ at time step $n, \Delta x$ denotes the length of spatial step. Implicit scheme is adopted for the difference of unsteady term and Eq. (13) is further rearranged as:

$$
T_{i}^{n}=\left(T_{i}^{n-1}+\frac{\Delta t}{A_{0} \rho c_{p} R} T_{o}+u^{n} \frac{\Delta t}{\Delta x} T_{i-1}^{n}\right) /\left(1+u^{n} \frac{\Delta t}{\Delta x}+\frac{\Delta t}{A_{0} \rho c_{p} R}\right), u^{n}>0
$$

where $\Delta t$ denotes time step size. When flow direction changes $\left(u^{n}<0\right)$, which usually occurs in meshed networks and the inlet boundary conditions will accordingly change, then the following equation yields:

$$
T_{i}^{n}=\left(T_{i}^{n-1}+\frac{\Delta t}{A_{0} \rho c_{p} R} T_{o}-u^{n} \frac{\Delta t}{\Delta x} T_{i+1}^{n}\right) /\left(1-u^{n} \frac{\Delta t}{\Delta x}+\frac{\Delta t}{A_{0} \rho c_{p} R}\right), u^{n}<0
$$

By extending the thermal model from $\mathrm{DH}$ pipeline to network, dynamic temperature distribution of DH network can be simulated via its initial temperature distribution, the supply temperature of heat source and the flow rate distribution and flow directions solved by hydraulic model. Besides, for meshed DH networks, the confluence nodes are the keys to handle, which generally connect several pipe branches together as shown in Fig.3 $[5,6,35]$. According to the energy conservation law, the fusion temperature of confluence node is calculated by Eqs. (17) and (18):

$$
\begin{gathered}
\sum_{k=1}^{n}\left(m_{\text {in }, k} \cdot T_{\text {in }, k}\right)=T_{\text {out }} \cdot \sum_{k=1}^{m}\left(m_{\text {out }, k}\right) \\
T_{\text {out }}=T_{\text {out }, k}, k=1,2,3, \ldots, m
\end{gathered}
$$




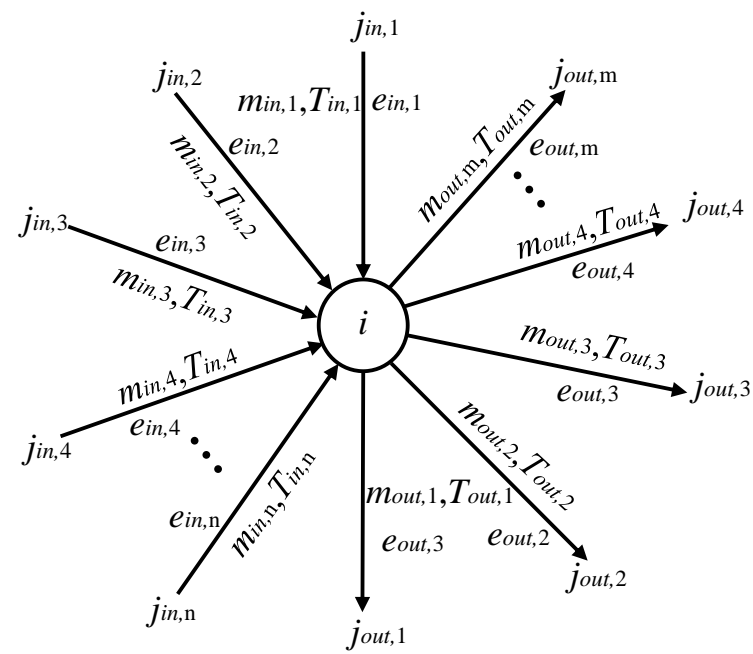

Fig.3. Confluence node $i$ with $(m+n)$ branches connected

\subsection{Thermo-hydraulic coupled calculation}

Hydraulic and thermal characteristics are closely related in DH network. Varying hydraulic conditions will lead to the variation of thermal conditions, and vice versa. Hence, analysis on thermo-hydraulic coupled conditions are inevitable for fast and accurate simulation of meshed DH network, which is largely dependent on the correct determination of inlet boundary condition for each pipeline.

\subsubsection{BFS based topology sorting of DH pipelines}

Confluence nodes are common in meshed DH networks, where the flow direction of hot water within pipeline may change with varying flow rates, and the inlet and outlet boundary conditions will accordingly vary. Meanwhile, the solution to thermohydraulic conditions is determined by the inlet boundary conditions of each pipeline, which is largely dependent on the accurate branch traversal of the network. Efficient 
topology sorting is therefore necessary for accurate node and branch traversals of DH network under each time step to ensure correct calculation sequence of each pipeline.

As the basic topology sorting algorithm for directed graphs, the main idea of BFS method is systematically exploring branches to discover the nodes that connecting the source node [36]. This method has been applied in many fields such as physics [37], computer graphics [38], optics [39] and mechanism [40], etc., while no literature concerning with the DH network. For meshed DH networks, an improved BFS method is applied with the index matrix $\left(P_{k}\right)$ introduced. $P_{k}$ has two columns. Its row numbers denote branch numbers, and the first and second columns represent inflow and outflow node indices of the connected branch. Taking Fig.4 as an example, where a small-scaled DH network with one heat source and three substations is presented. And $P_{k}$ is summarized in Table 1.

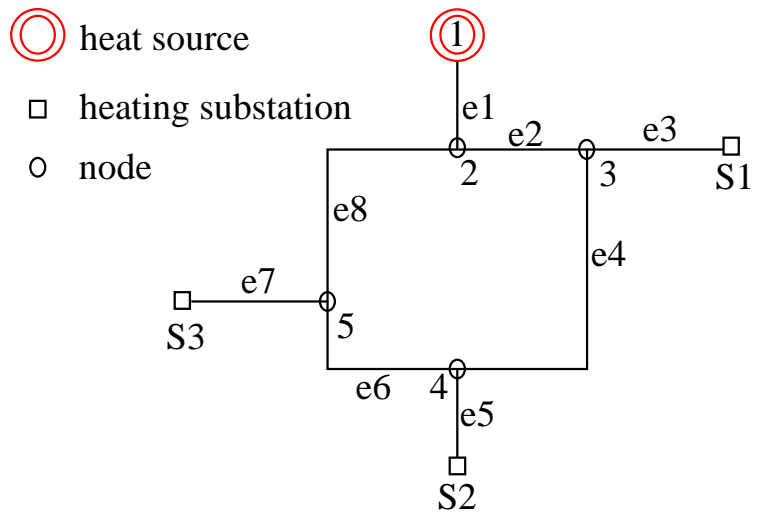

Fig.4. Layout of a small-scaled DH network

Table 1. Matrix $P_{k}$ of the small-scaled DH network

\begin{tabular}{cccccc}
\hline branch number & inflow node & outflow node & branch number & inflow node & outflow node \\
\hline e1 & 1 & 2 & e5 & 4 & S2 \\
\hline
\end{tabular}




\begin{tabular}{cccccc}
\hline e2 & 2 & 3 & e6 & 5 & 4 \\
e3 & 3 & S1 & e7 & 5 & S3 \\
e4 & 3 & 4 & e8 & 2 & 5 \\
\hline
\end{tabular}

During node traversal of the whole network, a heat source is considered as the initial node, then other nodes can be subsequently accessed via $P_{k}$. The branch traversal is performed based on $P_{k}$ and the traversal result of nodes, where the outflow branches of each sequenced nodes can be obtained. Fig. 5 shows the node traversal flowchart of meshed networks, and the procedure is summarized as follow:

(1) Initialize the traversal queue (a vector with variable length used to save the nodes to be traversed, denoted as $q$, and $q$ is initialized as an empty set), traversal results (denoted as $V_{\text {result }}$ and initialized as an empty set) and accessed flags (denoted as $F_{\text {flag }}$ and $F_{\text {flag }}$ is initialized as zero for all nodes), input $P_{k}$ matrix based on the topology of specific DH network;

(2) Put all the node numbers of heat sources into $q$;

(3) Assign $i=q_{1}$ (the first element of $q$ ), find the outflow node $j$ of node $i$ (the flow direction is from node $i$ to node $j$ ), access $i$ and update its accessed flag, remove $q_{1}$ and put $i$ to the end of $V_{\text {result }}$, then put node $j$ to the head of $q$;

(4) Find the inflow node $k$ of node $j$ (the flow direction is from node $k$ to node $j$ ), if the number of inflow nodes is more than one and all the inflow nodes have been accessed, then access node $j$ and update its accessed flag, otherwise the node $j$ cannot be accessed, then put $k$ to the head of $q$ and access $k$; 
(5) Repeat step 3 and 4 until accessed flags of all nodes have been updated.

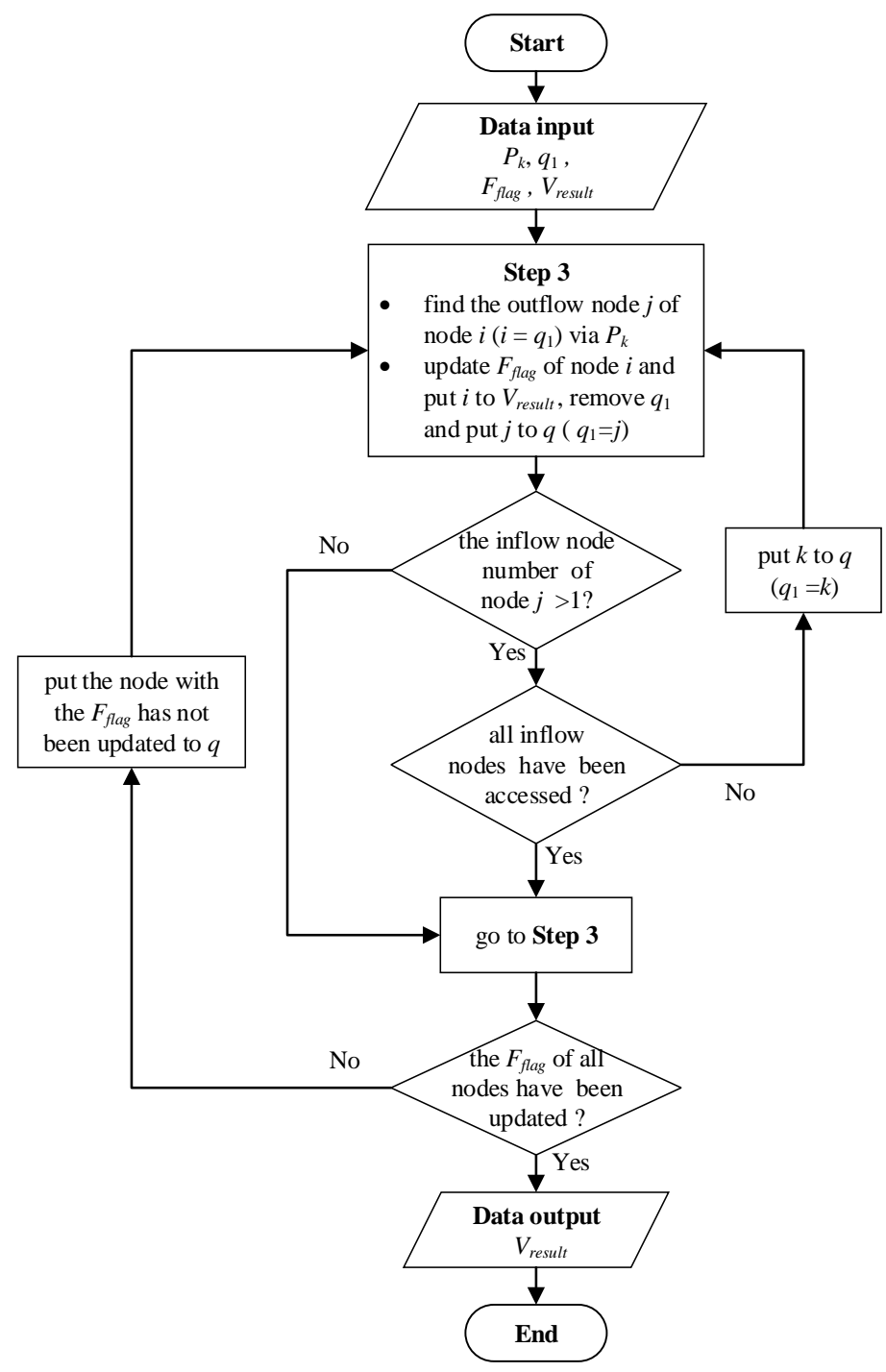

Fig.5. Flowchart of node traversal

\subsubsection{Calculation procedure}

Thermo-hydraulic coupled analysis of DH network can be realized with the efficiently conducted node and branch traversals, therefore, the inlet boundary conditions of all pipelines are determined. Flow rates and flow directions within DH network are obtained by solving the hydraulic model, then temperature transients can be calculated. 
Detailed coupled calculation procedure is presented in Fig.6, where $T_{w}$ is outdoor temperature vector, $N$ is the vector of control volume number, $D$ is the vector of pipeline internal diameter, $G_{y i}$ is flow ratio, which represents the ratio of real flow rate to the designed value and $t_{g_{2}}$ is the primary supply temperature of substation, whose dynamic variations can indicate the thermal transients of DH networks. The calculation sequence of each pipeline is firstly determined for initial hydraulic and thermal calculations based on the improved BFS method. In each iteration step, the results of hydraulic model are regarded as the input of thermal dynamic model, and the output of thermal part can also affect the solution of hydraulic conditions in the next iteration. $P_{k}$ is updated when the direction of flow changes, then the traversal results of node and branch are accordingly updated. 


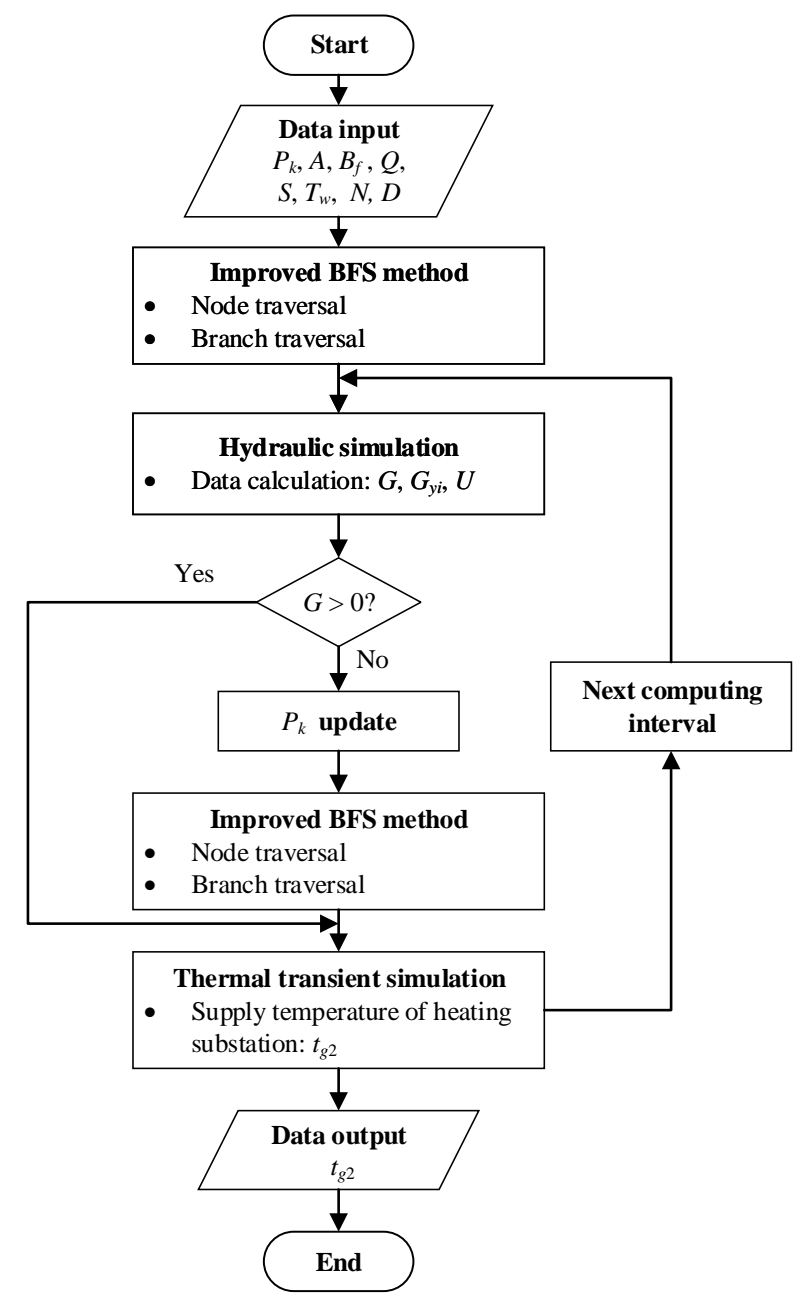

Fig.6. Flowchart of thermo-hydraulic coupled calculation

\section{Numerical verification}

To demonstrate the feasibilities of the thermo-hydraulic coupled model, a case study was conducted. The proposed thermo-hydraulic coupled method is applied to the real meshed DH network in Shijiazhuang City (China) for thermal characteristic analysis. Simulation codes are realized in MTALAB environment, which are performed on a laptop with four-core, $2 \mathrm{GHz}$ CPU and 8 GB RAM. And the computation time is recorded utilizing the MATLAB commands "tic \& toc".

\subsection{DH Network information of the case study}


Topology of the meshed DH network is shown in Fig. 7. This network has one heat source, 74 substations, 2 loops, 153 nodes and 155 branches. The supply temperature is controlled via weather compensation control strategy for both primary and secondary networks, which is shown in Fig. A, it indicates that the supply temperature of heat source and substations are regulated when outdoor temperature fluctuates. Besides, the primary flow rates of substations are controlled by PID controller via electronic control valves equipped in the primary side for ensuring the setpoint of secondary supply temperature, which is capable of precisely meeting the load demand for secondary network and functions as fine adjustment [10]. The designed supply and return temperatures of primary network are $110^{\circ} \mathrm{C}$ and $70^{\circ} \mathrm{C}$. And the designed supply and return temperatures of the secondary networks are $85^{\circ} \mathrm{C}$ and $60^{\circ} \mathrm{C}$. Fig. 8 shows the fluctuations of outdoor temperature and the regulated supply temperature of heat source. As is shown, supply temperature of heat source is changed with the variation of outdoor temperature. 


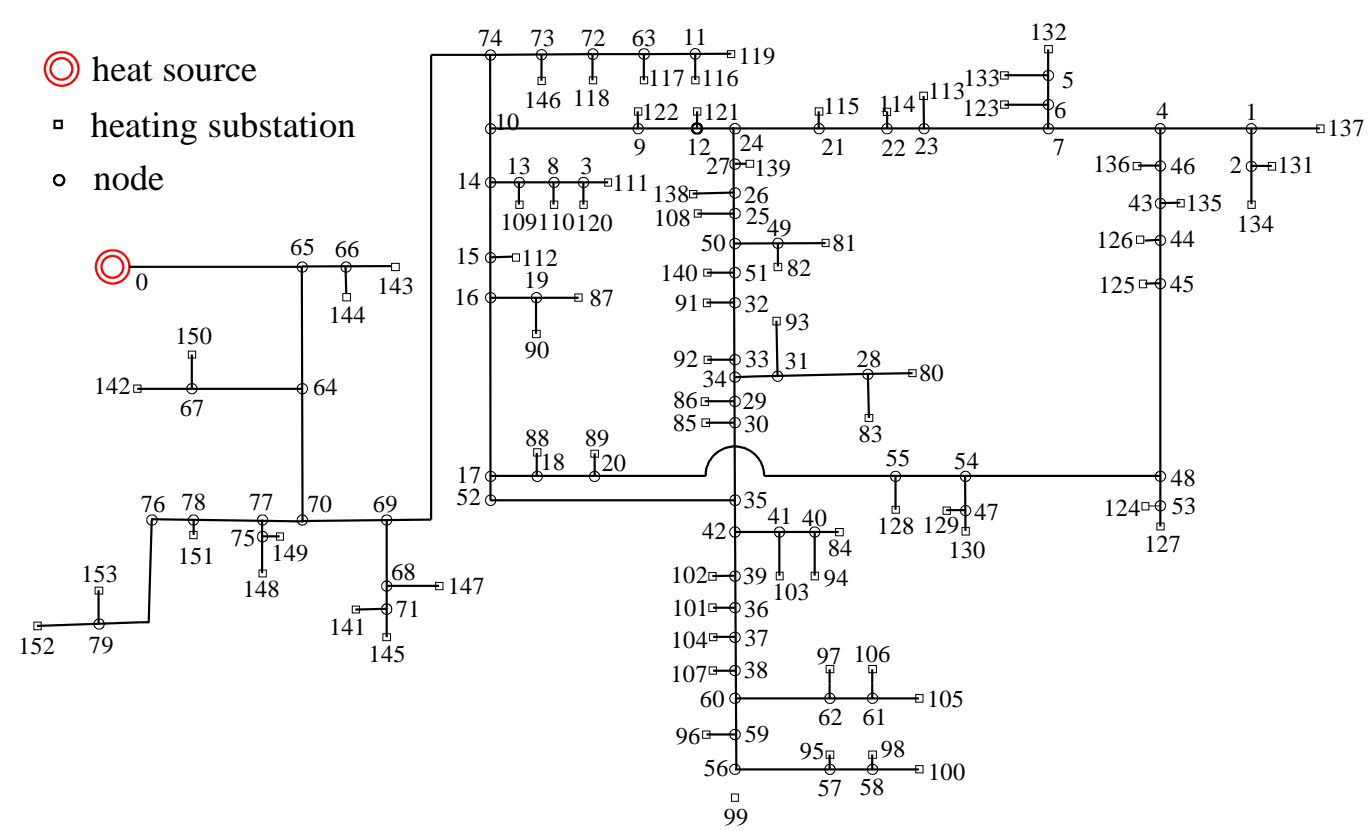

Fig.7. Topology of the studied DH network

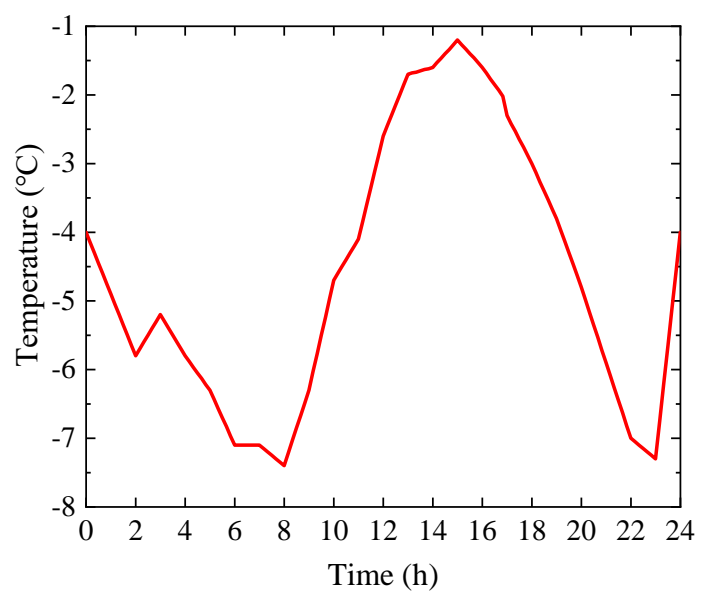

(a) Outdoor temperature

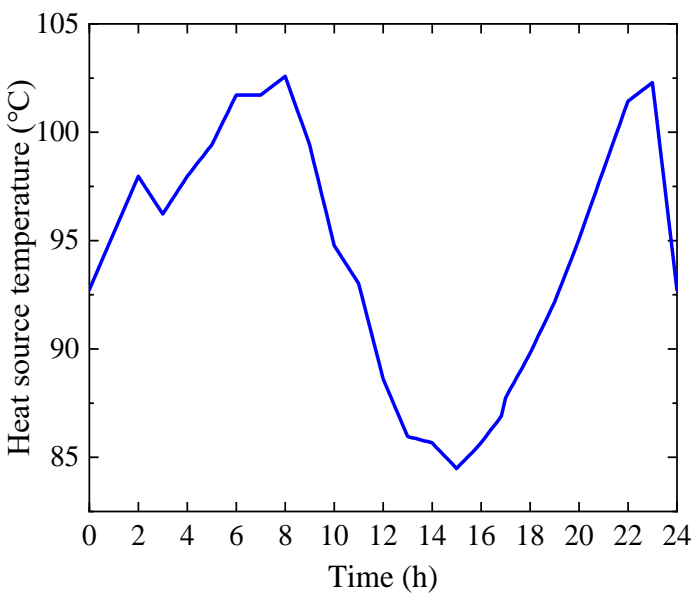

(b) Supply temperature of heat source

Fig. 8. Outdoor and heat source supply temperatures

\subsection{Independence analysis of hydraulic computation frequency}

The influences of hydraulic computation frequency on thermal dynamic characteristics, temperature decay and time delay of temperature waves, are studied and shown in Fig. 9. Substation 144 and 100 are adopted to conduct the analysis considering 
the large difference of transportation distance. Fig. 9 shows that the temperature wave trends of two substations under different hydraulic computation interval are generally consistent, while for substation 144, thermal dynamic characteristics are not distinct with hydraulic computation interval varying from 20 s to an hour, and the prediction deviations of thermal transients are larger for substation 100, since the substation 100 is further away from heat source and the dynamic characteristics are accordingly enlarged. With the decrease of hydraulic computation interval, simulated temperature variations gradually converge to certain temperature wave. And when the hydraulic computation interval is smaller than 10 minutes, simulated temperature variation changes very little.

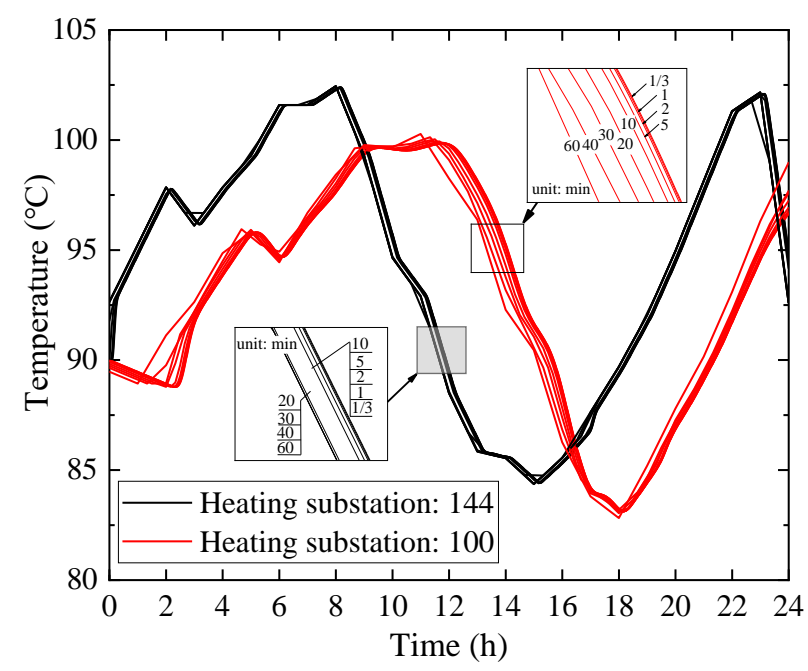

Fig. 9. Thermal transients under different hydraulic computation intervals

To further illustrate the convergence of thermal transient simulation method with respect to the hydraulic computation frequency (hydraulic computation times per unit time), a relatively small hydraulic computation interval, 20s is chosen as the standard 
interval to analyze the residuals of simulation results under different hydraulic computation intervals. Deviations of simulation temperature under 20s and hydraulic computation interval varying from 60 minutes to 1 minute are analyzed to indicate the convergence of the simulation error. Fig. 10 shows the residuals of substation 144 and 100 with hydraulic computation frequency varying from $1 / 60(1 / \mathrm{min})$ to $1(1 / \mathrm{min})$. Larger hydraulic computation frequency will lead to more accurate simulation results, residuals decreases rapidly first and converges zero when the hydraulic computation frequencies become infinite.

Temperature variations of substation 144 and 100 at specific time instance under different hydraulic computation frequencies are shown in Fig. 11. Three representative temperatures, the peak, valley and medium of temperature waves, are adopted to effectively illustrate the convergence of hydraulic computation frequency. It indicates that smaller hydraulic computation frequency will lead to larger calculation errors, which can be up to $3.0^{\circ} \mathrm{C}$ when hydraulic calculation is performed every hour for substation 100. Simulation temperatures of substation tend to be constant with hydraulic computation frequency increasing, which shows the good convergence of hydraulic computation frequency. Twenty-second hydraulic computation interval is therefore considered as the basic computation interval, and it equals to the time step of thermal transient prediction, which is recommended in Ref. [17]. Computing time under different hydraulic computation frequencies are shown in Fig. 12. And the computing time is approximately proportional to hydraulic computation frequency, since more 
thermal and hydraulic calculation iterations will be conducted under small hydraulic computation frequency. Hence, the range of hydraulic computation frequency should be restricted to reduce the computing burden. According to the above analysis, with tenminute hydraulic computation interval, the hydraulic computation interval independent numerical solution can be obtained, and taking both simulation error and computing time into account, ten-minute hydraulic computation interval is appropriate for both fast and accurate thermal dynamic simulation, of which the calculation error can be within $0.5^{\circ} \mathrm{C}$ and the computing time is around $10 \mathrm{~s}$ for the twenty-four-hour thermal dynamic simulation of the studied DH network.

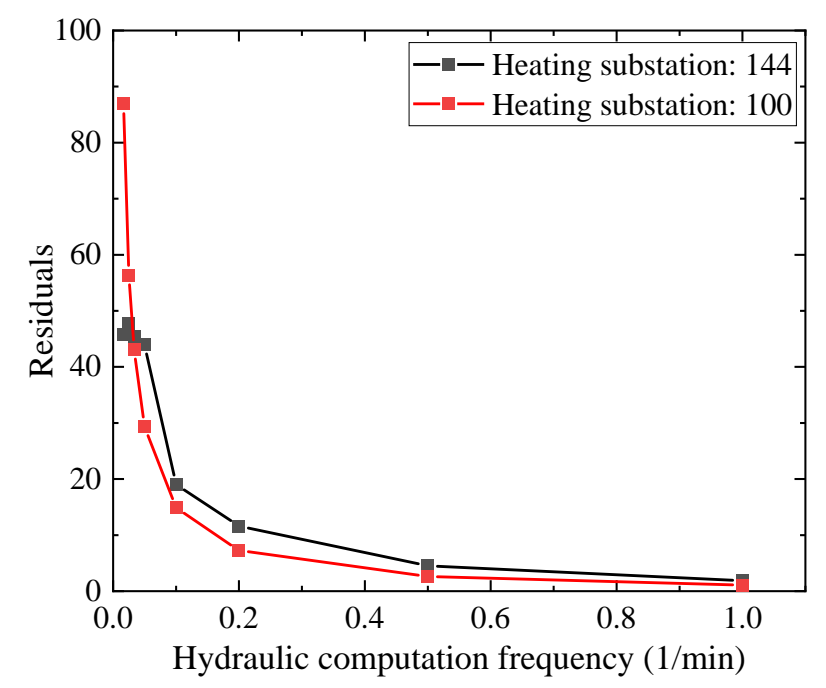

Fig. 10. Residuals under different hydraulic computation frequencies 


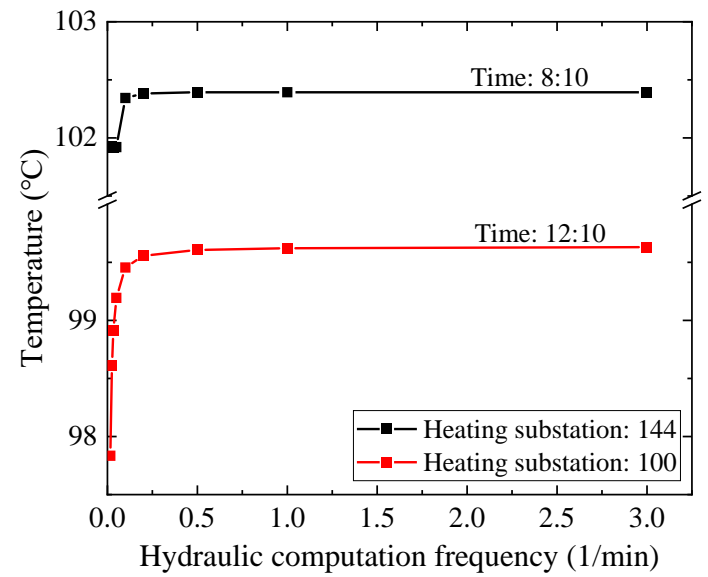

(a) Temperature of peak

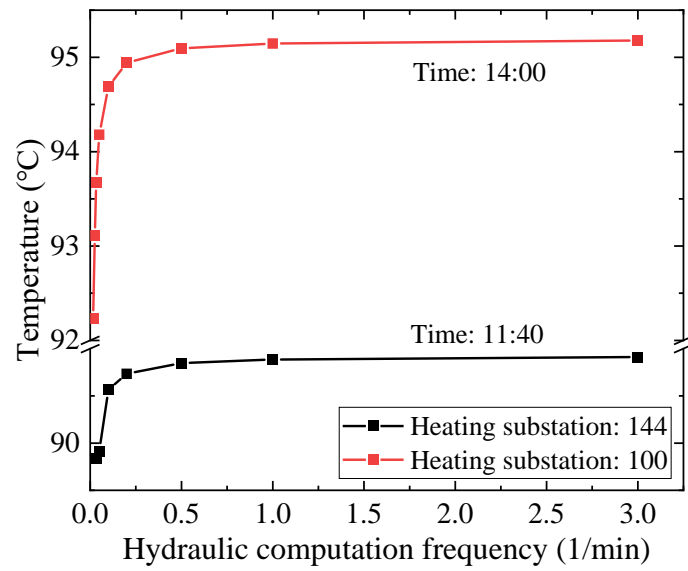

(b) Temperature of medium

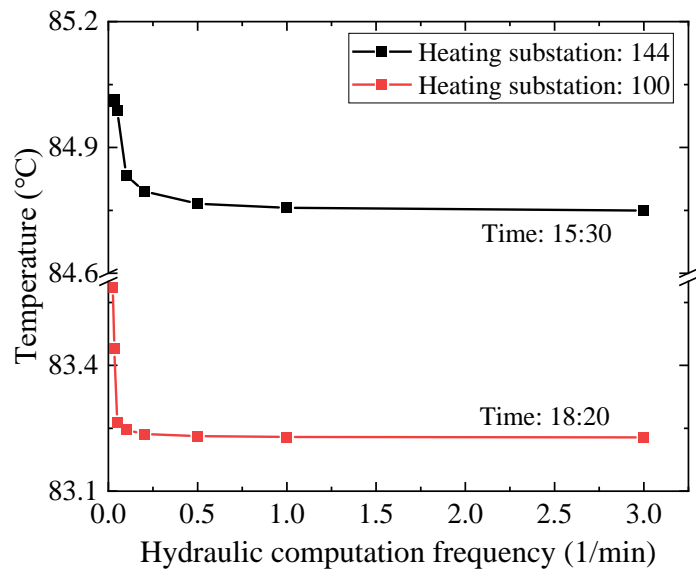

(c) Temperature of valley

Fig. 11. Temperature variations of substation 144 and 100 at specific time instance

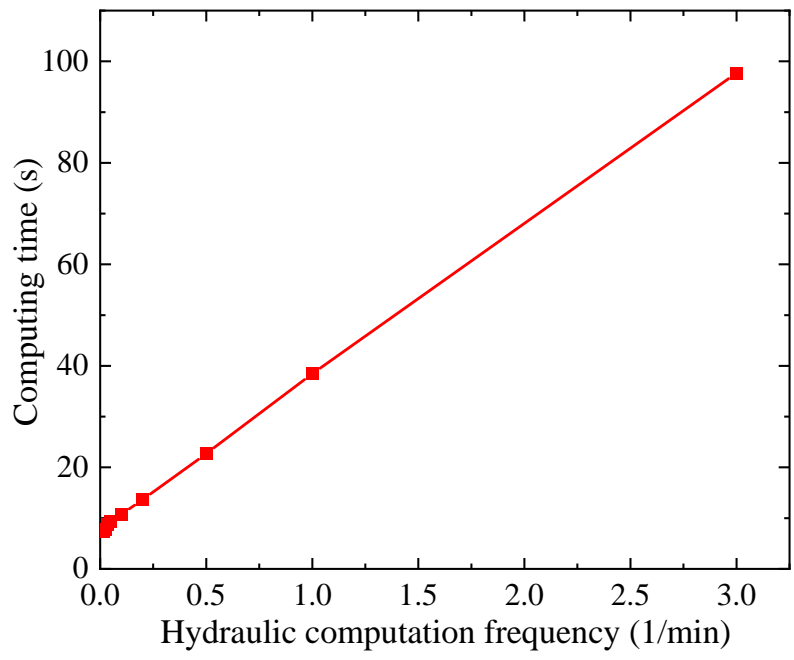

Fig. 12. Computing time under different hydraulic computation frequencies 


\section{Results and discussion}

\subsection{Thermal transient analysis}

Substation 100 is the last traversed node according to node traversal results. Directions of hot water within DH network are studied based on the improved BFS method, where the flow directions remain stable in a daily basis analysis in this case. Substation 144, 90 and 100 are selected for the analysis of thermal dynamic characteristics, of which the pipeline lengths are $1050 \mathrm{~m}, 9300 \mathrm{~m}$, and $14010 \mathrm{~m}$ from heat source, respectively. Ten-minute hydraulic computation interval is adopted for thermal transient analysis of DH networks. As is shown in Fig. 13, variation trends of temperature waves are consistent for the three substations, which means that the supply temperature variations at substations are mainly dependent on the fluctuations of heat source temperature. But the temperature delays and decays of the three substations are different, and the larger distance from heat source, the more transportation time and more temperature decay are observed.

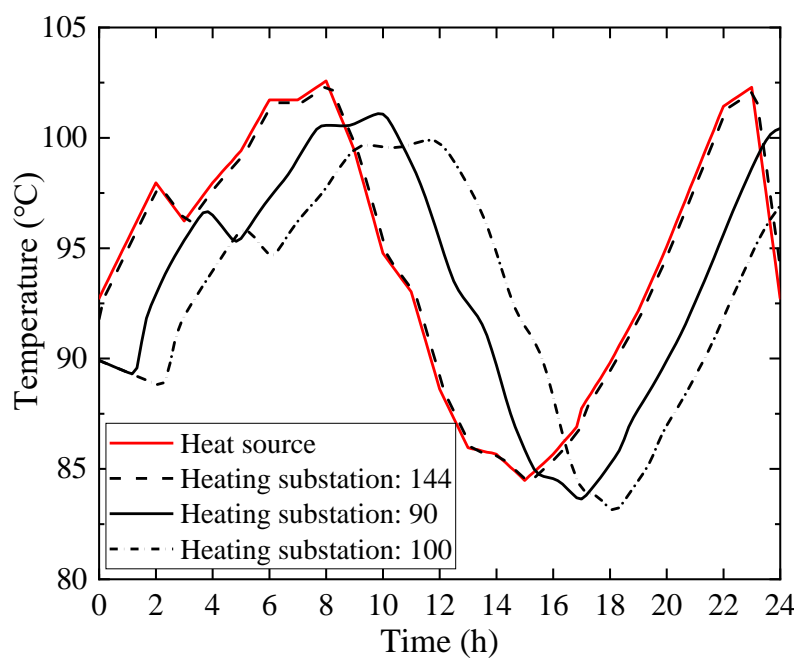

Fig. 13. Supply temperatures of heat source and three substations 
A specific path is selected for detailed thermal dynamic analysis as shown in Fig. 14, which connects the substation 144, 112, 90, 102 and 100. And variations of temperature wave peak (TP) are used to describe $\mathrm{DH}$ network thermal dynamics. Correlations between transportation distance and thermal dynamic characteristics of TP are shown in Fig. 15. Fig. 15 indicates that the time delay of temperature transportation is approximately proportional to the transportation distance, and the time delay of TP can be up to 210 minutes for substation 100. Besides, the temperature decays are almost uniformly enlarged along the path, since the heat loss is generated along the DH pipeline, and the temperature decay of substation 100 is up to $2.7^{\circ} \mathrm{C}$ in this case.

In addition, variations of TP are not in accordance with that of temperature wave valley (TV), which are also shown in Fig. 15. Time delay of the latter tends to be larger than that of the former when the distance from heat source is within $12.0 \mathrm{~km}$, and becomes smaller as distance beyond this range. This is due to the adaptive flow control of substations when outdoor temperature fluctuates. Mass flow rate variations and the temperature wave fluctuations of heat source are shown in Fig. 16. It indicates that the transportation time difference between mass flow rates and temperature wave exists, and there is around two-hour delay for the flow rate wave compared with temperature wave of heat source, which will lead to the difference between pipeline mass flow rates corresponding to TP and TV as the temperature wave propagates. And the mass flow rate difference is varying along the selected path as shown in Fig. 17. The pipeline mass flow rate ratio is defined as the ratio of pipeline mass flow rate difference corresponding 
to TP and TV to pipeline mass flow rate corresponding to TP. It shows that the pipeline mass flow rates corresponding to TV is larger than that of TP when the pipeline is far away from the heat source. And the enlarged mass flow rates will accelerate propagation of temperature wave within the network. The time delay and temperature decay are up to 190 minutes and $1.4^{\circ} \mathrm{C}$ for $\mathrm{TV}$, while the temperature decays of $\mathrm{TP}$ are larger than that of the TV, since temperature difference between TP and TV is approximately up to $16^{\circ} \mathrm{C}$ and more heat loss will be caused for TP.

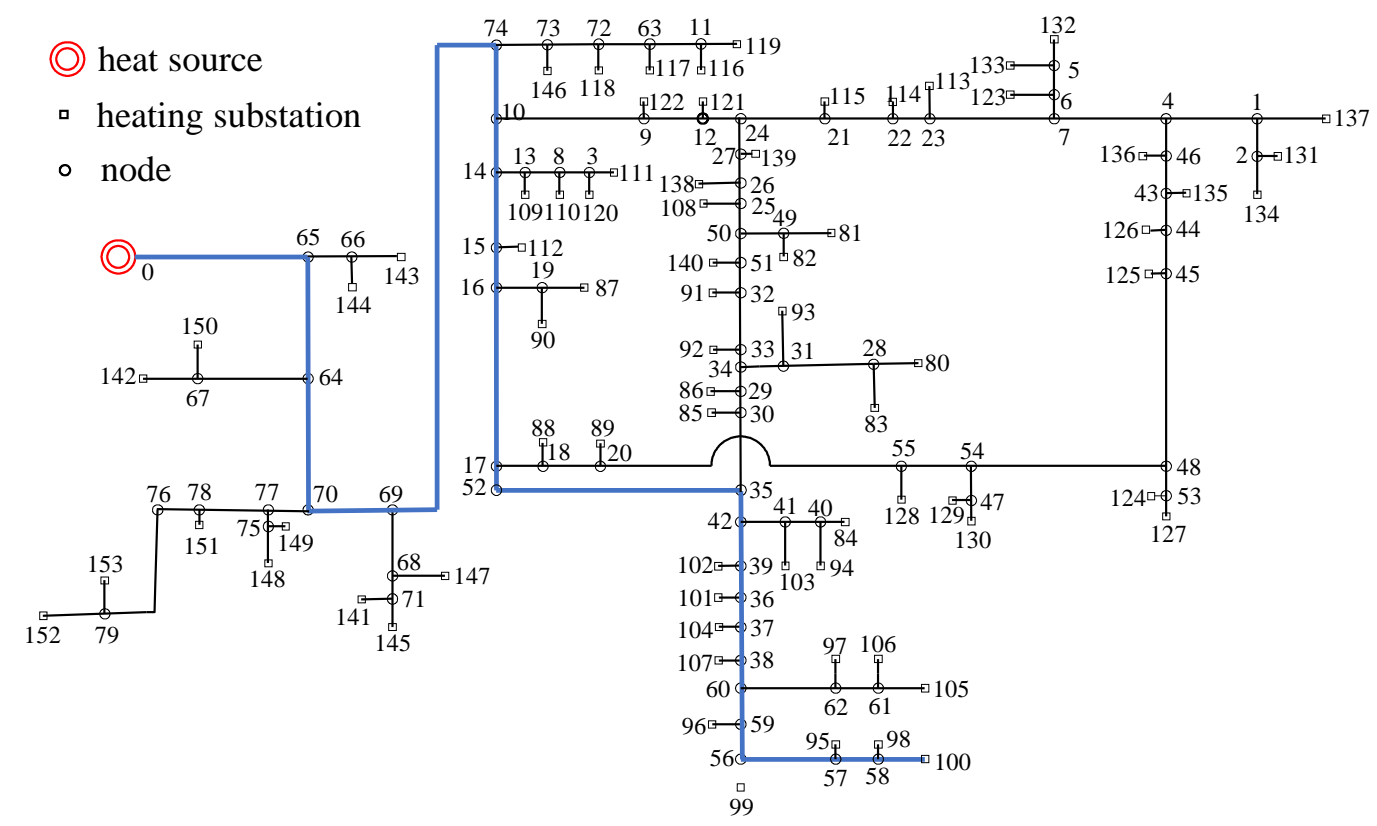

Fig. 14. Selected path (blue and thick line) of DH network 


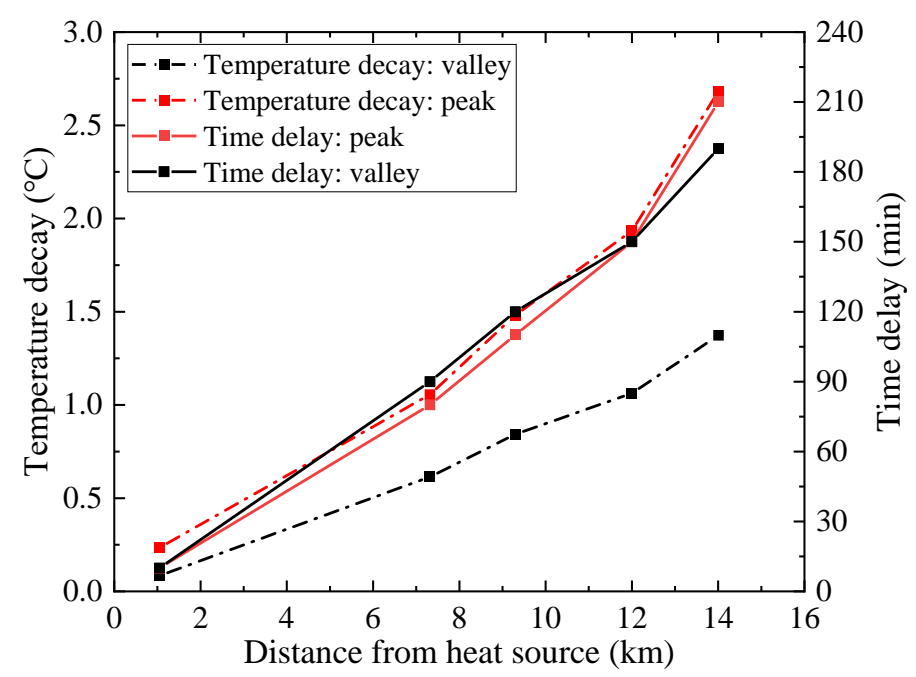

Fig. 15. Dynamic characteristics of TP and TV along the selected path

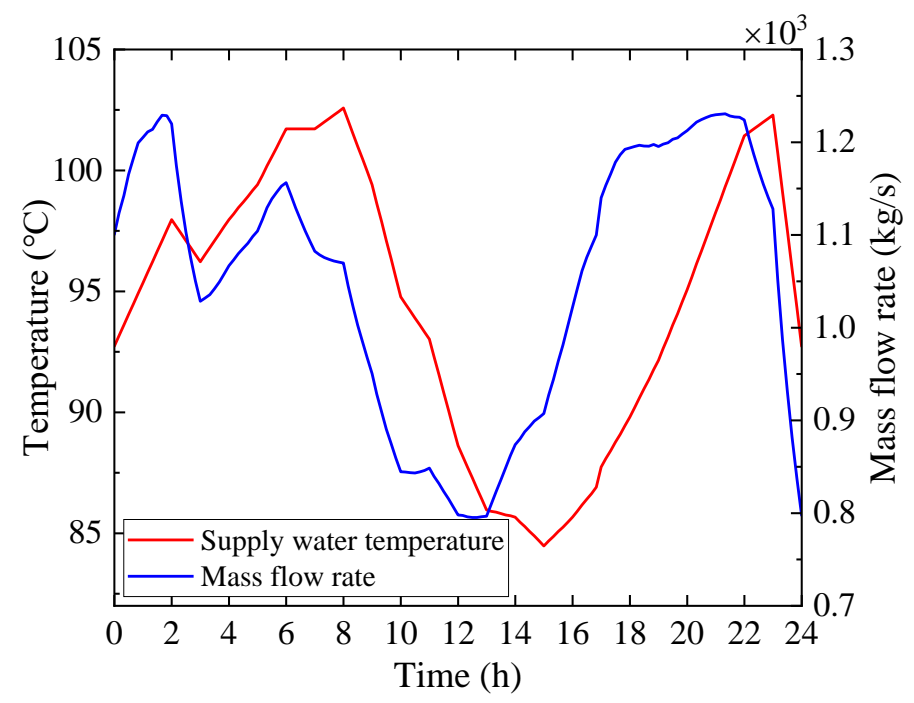

Fig. 16. Supply temperature and mass flow rate of heat source

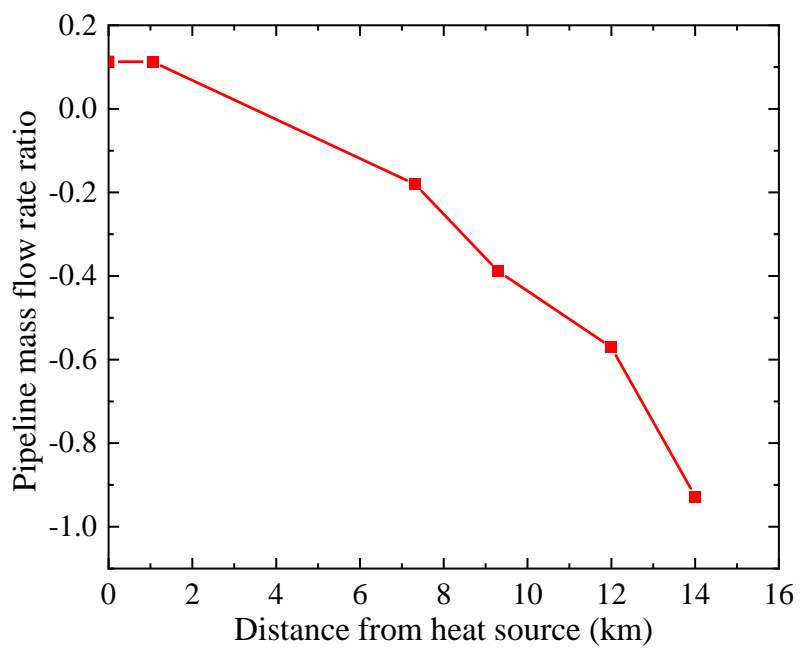


Fig. 17. Pipeline mass flow rate ratio along the select path

\subsection{Influence of substation flow rates on thermal transients}

Furthermore, the influences of primary flow rates of substation on thermal transients are also studied and shown in Fig. 18. Considering the different distance from heat source, substation 144, 90 and 100 are selected for this purpose, of which the primary mass flow rates are varying within $\pm 50 \%$. It indicates that temperature wave dynamic characteristics of substation are influenced by its own mass flow rate, and the further away from heat source, the larger influence will be caused. For the substations studied in this paper, temperature wave dynamics of substation 100 are significantly varying when its mass flow rate ranges from $7.1 \mathrm{~kg} / \mathrm{s}$ to $2.4 \mathrm{~kg} / \mathrm{s}$, since substation 100 is the last traversed node, and its varying mass flow rate can greatly affect the terminal pipeline flow rate.

Meanwhile, larger mass flow rates will lead to less heat loss and faster temperature wave propagation. The maximum variations of temperature decay and time delay are around $0.3^{\circ} \mathrm{C}$ and 30 minutes, respectively. However, the influences of mass flow rate on other substation temperature wave dynamics are not distinct, since the mass flow rates are relatively low, of which the total mass flow rate will not be greatly changed. 


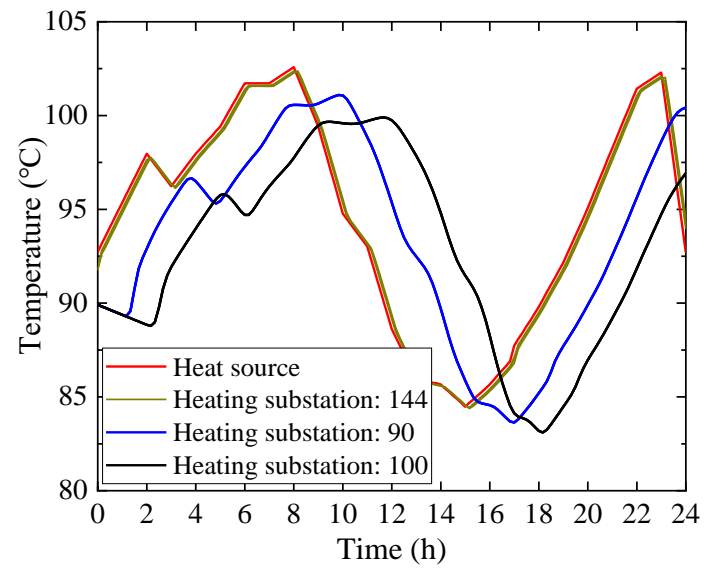

(a) Varying flow rates of substation 144

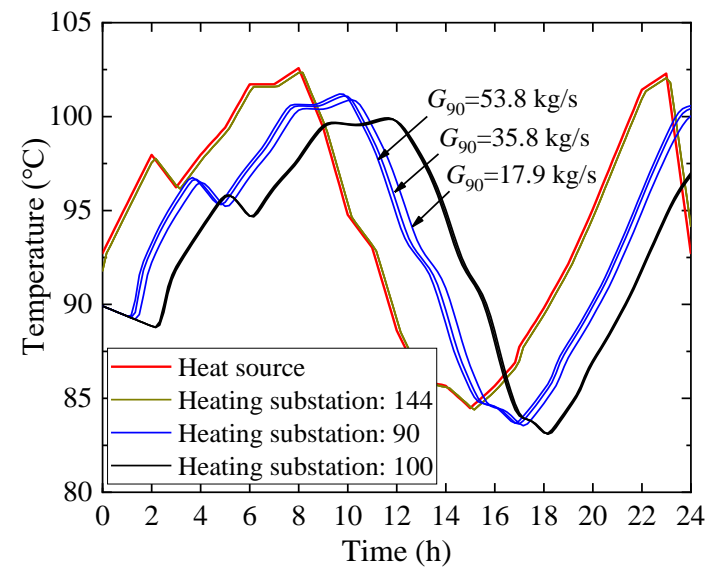

(b) Varying flow rates of substation 90

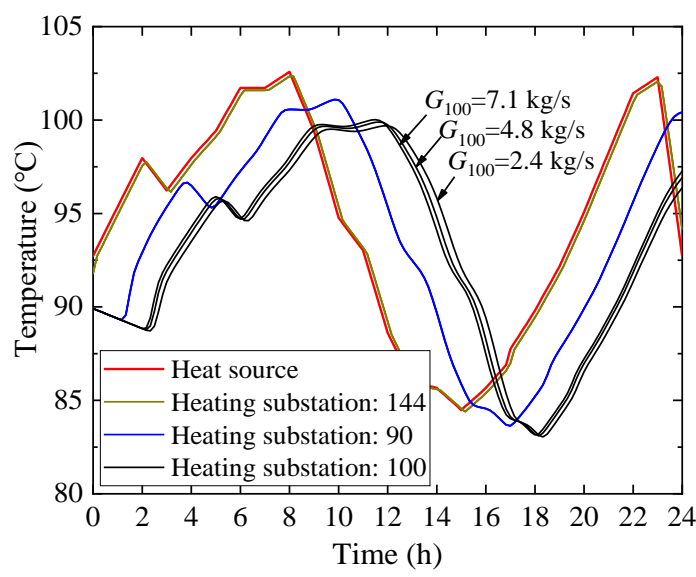

(c) Varying flow rates of substation 100

Fig. 18. Temperature variations of substations with varying flow rates

\section{Conclusions}

In this paper, a thermo-hydraulic coupled model for meshed DH network is proposed based on the improved BFS method. The coupled model is capable of simulating the thermal dynamics of meshed DH networks, as well as the networks with multiple heat sources. The following conclusions are drawn:

(1) The improved BFS method can achieve the efficient calculation sequence of DH pipelines, which is essential to the thermal transient extension from $\mathrm{DH}$ pipeline to network. Simulation performances of thermal dynamics are influenced by hydraulic 
computation frequency. Higher computation frequency will lead to more accurate thermal transient simulation results, while inducing larger computing burden. The proposed thermo-hydraulic coupled computation method is convergent with respect to the increase of hydraulic computation frequency, and ten-minute hydraulic computation interval is recommended in this studied case, of which the prediction error can be within $0.5^{\circ} \mathrm{C}$ and the computation time is around $10 \mathrm{~s}$ for the twenty-four-hour thermal dynamic simulation.

(2) Thermal transients of DH networks are distinct for this meshed system. And the temperature wave decay and time delay of substations are varying considering the different distance from heat source. For the case studied in this paper, temperature decay is up to $2.7^{\circ} \mathrm{C}$ and the maximum time delay is around 210 minutes.

(3) For substations, the time delay and temperature decay are changed with the fluctuation of outdoor temperature (variation of heat source temperature). Lower outdoor temperature will lead to larger temperature decays of temperature wave, while the time delay variations of substations are inconsistent with the fluctuation of outdoor temperature.

(4) Temperature dynamic characteristics of substation can be distinctly influenced by its own mass flow rate, and the further away from heat source, the larger influence will be caused. But the mass flow rate influences on temperature wave thermal transients of other substations are not distinct. For the substations studied in this paper, 
the maximum temperature decay and time delay variations are around $0.3{ }^{\circ} \mathrm{C}$ and 30 minutes.

Fast and accurate thermal transient prediction is essential to the operation control of meshed DH networks. Thermo-hydraulic coupled method can efficiently predict thermal dynamics of $\mathrm{DH}$ networks considering the hydraulic and thermal conditions are tightly linked. And with the predictive control of DH networks being widely discussed presently, the presented thermo-hydraulic coupled method can be used to optimize the supply temperature of heat sources coupled with optimization algorithm.

\section{Acknowledgements}

This work was supported by the Natural Science Foundation of Tianjin (No. 19JCQNJC07200) and the National Key R\&D Program of China (No. 2018YFC0705000).

\section{Appendix A}

The weather compensation control strategy is shown in Fig. A, which is drawn based on the fluctuation range of outdoor temperature in this case and Refs. [41] and [42]. 


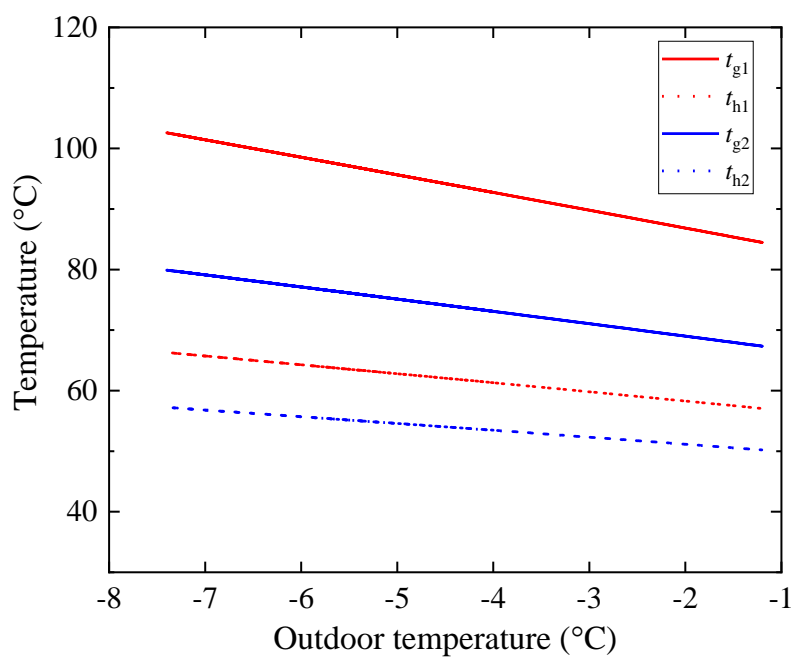

Fig. A. Weather compensation control strategy

where $t_{g 1}$ and $t_{h 1}$ are supply and return temperatures of heat source, $t_{g 2}$ and $t_{h 2}$ are secondary supply and return temperatures of substation.

\section{References}

[1] Gong M, Werner S. An assessment of district heating research in China. Renewable Energy. 2015;84:97-105.

[2] Li Y, Rezgui Y, Zhu HX. District heating and cooling optimization and enhancement

- Towards integration of renewables, storage and smart grid. Renewable and Sustainable Energy Reviews. 2017;72:281-294.

[3] Lund H, Werner S, Wiltshire R, Svendsen S, Thorsen JE, Hvelplund F, et al. 4th generation district Heating (4GDH). Integrating smart thermal grids into future sustainable energy systems. Energy. 2014; 68:1-11.

[4] Lake A, Rezaie B, Beyerlein S. Review of district heating and cooling systems for a sustainable future. Renewable and Sustainable Energy Reviews. 2017;67:417-425. 
[5] Wang D, Zhi YQ, Jia HJ, Hou K, Zhang SX, Du W, et al. Optimal scheduling strategy of district integrated heat and power system with wind power and multiple energy stations considering thermal inertia of buildings under different heating regulation modes. Applied Energy. 2019;240:341-358.

[6] Wang H, Meng H. Improved thermal transient modeling with new 3-order numerical solution for a district heating network with consideration of the pipe wall's thermal inertia. Energy. 2018;160:171-183.

[7] Stevanovic VD, Prica S, Maslovaric B, Zivkovic B, Nikodijevic S. Efficient numerical method for district heating system hydraulics. Energy Conversion and Management. 2007;48:1536-1543.

[8] Ben Hassine I, Eicker U. Impact of load structure variation and solar thermal energy integration on an existing district heating network. Applied Thermal Engineering. 2013;50:1437-1446.

[9] Vesterlund M, Toffolo A, Dahl J. Simulation and analysis of a meshed district heating network. Energy Conversion and Management. 2016;122:63-73.

[10] Wang YR, You SJ, Zhang H, Zheng WD, Zheng XJ, Miao QW. Hydraulic performance optimization of meshed district heating network with multiple heat sources. Energy. 2017;126:603-621.

[11] Zhou SJ, Li HM, Gong P, Tian MC. Hydraulic modeling of double-source and ringshaped heating networks. Applied Thermal Engineering. 2017;119:215-221. 
[12] Wang H, Wang HY, Zhu T. A new hydraulic regulation method on district heating system with distributed variable-speed pumps. Energy Conversion and Management. 2017;147:174-189.

[13] Wang H, Wang HY, Zhou HJ, Zhu T. Modeling and optimization for hydraulic performance design in multi-source district heating with fluctuating renewables. Energy Conversion and Management. 2018;156:113-129.

[14] Yan AB, Zhao J, An QS, Zhao YL, Li HL, Huang YJ. Hydraulic performance of a new district heating systems with distributed variable speed pumps. Applied Energy. 2013;112:876-885.

[15] Guelpa E, Toro C, Sciacovelli A, Melli R, Sciubba E, Verda V. Optimal operation of large district heating networks through fast fluid-dynamic simulation. Energy. 2016;102:586-595.

[16] Li ZG, Wu WC, Shahidehpour M, Wang JH, Zhang BM. Combined heat and power dispatch considering pipeline energy storage of district heating network. IEEE Transactions on Sustainable Energy. 2016;7:12-22.

[17] Wang YR, You SJ, Zhang H, Zheng XJ, Zheng WD, Miao QW, et al. Thermal transient prediction of district heating pipeline: Optimal selection of the time and spatial steps for fast and accurate calculation. Applied Energy. 2017;206:900-910.

[18] Gabrielaitiene I, Bøhm B, Sunden B. Modelling temperature dynamics of a district heating system in Naestved, Denmark - A case study. Energy Conversion and Management. 2007;48:78-86. 
[19] Gabrielaitienė I, Bøhm B, Sundén B. Dynamic temperature simulation in district heating systems in Denmark regarding pronounced transient behaviour. Journal of Civil Engineering and Management. 2011;17:79-87.

[20] Hao L, Xu F, Chen Q, Wei MS, Chen L, Min Y. A thermal-electrical analogy transient model of district heating pipelines for integrated analysis of thermal and power systems. Applied Thermal Engineering. 2018;139:213-221.

[21] Schwarz MB, Mabrouk MT, Silva CS, Haurant P, Lacarrière B. Modified finite volumes method for the simulation of dynamic district heating networks. Energy. 2019;182:954-964.

[22] Stevanovic VD, Zivkovic B, Prica S, Maslovaric B, Karamarkovic V, Trkulja V. Prediction of thermal transients in district heating systems. Energy Conversion and Management. 2009;50:2167-2173.

[23] Wang H, Wang HY, Zhou HJ, Zhu T. Optimization modeling for smart operation of multi-source district heating with distributed variable-speed pumps. Energy. 2017; 138:1247-1262.

[24] Van der Heijde B, Fuchs M, Tugores CR, Schweiger G, Sartor K, Basciotti D, et al. Dynamic equation-based thermo-hydraulic pipe model for district heating and cooling systems. Energy Conversion and Management. 2017;151:158-169.

[25] Badami M, Fonti A, Carpignano A, Grosso D. Design of district heating networks through an integrated thermo-fluid dynamics and reliability modelling approach. Energy. 2018;144:826-838. 
[26] Merkert L, Listmann K, Hohmann S. Optimization of thermo-hydraulic systems using multiparametric delay modeling. Energy. 2019;189:116-125.

[27] Oppelt T, Urbaneck T, Gross U, Platzer B. Dynamic thermo-hydraulic model of district cooling networks. Applied Thermal Engineering. 2016;102:336-345.

[28] Liu XZ, Wu JZ, Jenkins N, Bagdanavicius A. Combined analysis of electricity and heat networks. Applied Energy. 2016;162:1238-1250.

[29] Guelpa E, Sciacovelli A, Verda V. Thermo-fluid dynamic model of large district heating networks for the analysis of primary energy savings. Energy. 2019;184:34-44. [30] Gu W, Wang J, Lu S, Luo Z, Wu CY. Optimal operation for integrated energy system considering thermal inertia of district heating network and buildings. Applied Energy. 2017; 199:234-246.

[31] Wang JD, Zhou ZG, Zhao JN. A method for the steady-state thermal simulation of district heating systems and model parameters calibration. Energy Conversion and Management. 2016;120:294-305.

[32] Wang N, You SJ, Wang YR, Zhang H, Miao QW, Zheng XJ, et al. Hydraulic resistance identification and optimal pressure control of district heating network. Energy and Buildings. 2018;170:83-94.

[33] Duquette J, Rowe A, Wild P. Thermal performance of a steady state physical pipe model for simulating district heating grids with variable flow. Applied Energy. 2016;178:383-393. 
[34] Steer KCB, Wirth A, Halgamuge SK. Control period selection for improved operating performance in district heating networks. Energy and Buildings. 2011;43:605-613.

[35] Cao Y, Wei W, Wu L, Mei SW, Shahidehpour M, Li ZY. Decentralized Operation of Interdependent Power Distribution Network and District Heating Network: A Market-Driven Approach. IEEE Transactions on Smart Grid. 2019;10:5374-5385.

[36] Cormen TH, Leiserson CE, Rivest RL, Stein C. Introduction to algorithms. 3th ed. America: The MIT Press; 2009.

[37] Zhou B, He Z, Wang NX, Wang BH. A method of characterizing network topology based on the breadth-first search tree. Physica A-Statistical Mechanics and its Applications. 2016;450:682-686.

[38] Calla LAR, Perez LJF, Montenegro AA. A minimalistic approach for fast computation of geodesic distances on triangular meshes. Computers \& Graphics-UK. 2019;84:77-92.

[39] Garcia LL, Arellano AG, Cruz-Santos W. A parallel path-following phase unwrapping algorithm based on a top-down breadth-first search approach. Optics and Lasers in Engineering. 2020;124.

[40] Sun W, Kong JY, Sun LB. A novel graphical joint-joint adjacent matrix method for the automatic sketching of kinematic chains with multiple joints. Mechanism and Machine Theory. 2020;150. 
[41] Jaćimovic B, Živković B, Genić S, Zekonja P. Supply water temperature regulation problems in district heating network with both direct and indirect connection. Energy and Buildings. 1998; 28:317-322.

[42] Ma XX. Research on dynamic thermal conditions of centralized heat-supply system based on pipe network performance. Taiyuan University of Technology. Taiyuan, 2017 (in Chinese). 